\title{
PET imaging of mGluR5 in Alzheimer's disease
}

\author{
Adam P. Mecca ${ }^{1,2}$, Julia W. McDonald ${ }^{1,2}$, Hannah R. Michalak ${ }^{1,2}$, Tyler A. Godek ${ }^{1,2}$, Joanna E. Harris ${ }^{1,2}$, \\ Erika A. Pugh ${ }^{1,2}$, Emily C. Kemp ${ }^{1,2}$, Ming-Kai Chen ${ }^{5}$, Arash Salardini ${ }^{4}$, Nabeel B. Nabulsi ${ }^{5}$, Keunpoong Lim ${ }^{5}$, \\ Yiyun Huang ${ }^{5}$, Richard E. Carson ${ }^{5}$, Stephen M. Strittmatter ${ }^{3,4,6^{*}}$ and Christopher H. van Dyck (1,2,3, $^{*}$ (D)
}

\begin{abstract}
Background: Metabotropic glutamate subtype 5 receptors (mGluR5) modulate synaptic transmission and may constitute an important therapeutic target in Alzheimer's disease (AD) by mediating the synaptotoxic action of amyloid- $\beta$ oligomers. We utilized the positron emission tomography (PET) radioligand $\left[{ }^{18} \mathrm{~F}\right] \mathrm{FPEB}$ to investigate mGluR5 binding in early AD.
\end{abstract}

Methods: Sixteen individuals with amnestic mild cognitive impairment $(\mathrm{MCl})$ due to $A D$ or mild $A D$ dementia who were positive for brain amyloid were compared to 15 cognitively normal (CN) participants who were negative for brain amyloid. Diagnostic groups were well balanced for age, sex, and education. Dynamic PET scans were acquired for $60 \mathrm{~min}$, starting at $60 \mathrm{~min}$ after the initial administration of up to $185 \mathrm{MBq}$ of $\left[{ }^{18} \mathrm{~F}\right] \mathrm{FPEB}$ using a bolus-plusconstant-infusion method ( $K_{\mathrm{bol}}=190 \mathrm{~min}$ ). Equilibrium modeling with a cerebellum reference region was used to estimate $\left[{ }^{18} \mathrm{~F}\right] \mathrm{FPEB}$ binding $\left(B P_{\mathrm{ND}}\right)$ to mGluR5. Analyses were performed with and without corrections for gray matter atrophy and partial volume effects.

Results: Linear mixed model analysis demonstrated a significant effect of group $(p=0.011)$ and the group $\times$ region interaction ( $p=0.0049)$ on $B P_{\mathrm{ND}}$. Post hoc comparisons revealed a significant reduction (43\%) in mGluR5 binding in the hippocampus of $A D\left(B P_{N D}=0.76 \pm 0.41\right)$ compared to $C N\left(B P_{N D}=1.34 \pm 0.58, p=0.003\right.$, unpaired $t$ test $)$ participants, and a nonsignificant trend for a reduction in a composite association cortical region in $A D\left(B P_{\mathrm{ND}}=\right.$ $1.57 \pm 0.25)$ compared to $C N\left(B P_{N D}=1.86 \pm 0.63, p=0.093\right)$ participants. Exploratory analyses suggested additional mGluR5 reductions in the entorhinal cortex and parahippocampal gyrus in the AD group. In the overall sample, hippocampal mGluR5 binding was associated with episodic memory scores and global function.

Conclusions: ${ }^{18}$ F]FPEB-PET revealed reductions in hippocampal mGluR5 binding in early AD. Quantification of mGluR5 binding in AD may expand our understanding of AD pathogenesis and accelerate the development of novel biomarkers and treatments.

Keywords: $m$ GluR5, Glutamate receptor, Alzheimer's disease, $\left[{ }^{18} \mathrm{~F}\right] \mathrm{FPEB}, \mathrm{PET}$

\section{Introduction}

Metabotropic glutamate subtype 5 receptors (mGluR5) are seven-transmembrane $\mathrm{G}$ protein-coupled receptors located in excitatory synapses [1] and in glial cells [2]. They are distributed throughout the cortex and hippocampus

\footnotetext{
* Correspondence: Stephen.strittmatter@yale.edu;

christopher.vandyck@yale.edu

${ }^{3}$ Department of Neuroscience, Yale University School of Medicine, New Haven, CT, USA

${ }^{1}$ Alzheimer's Disease Research Unit, Yale University School of Medicine, One Church Street, 8th Floor, New Haven, CT 06510, USA

Full list of author information is available at the end of the article
}

where they modulate synaptic transmission $[3,4]$. In rat brain, they are localized primarily postsynaptically $[5,6]$, but also presynaptically [7]. In primate prefrontal cortex, a substantial proportion are presynaptic [8]. In preclinical models of $\mathrm{AD}$, mGluR5 has been hypothesized to mediate amyloid- $\beta$ oligomer $(A \beta o)$ toxicity via several mechanisms, including promoting the clustering of $A \beta O$ as an extracellular scaffold for mGluR5 [9] and serving as a co-receptor for $\mathrm{A} \beta \mathrm{b}$ bound to cellular prion protein $\left(\operatorname{PrP}^{\mathrm{c}}\right)$ for postsynaptic activation of the tyrosine kinase Fyn $[10,11]$.

(c) The Author(s). 2020 Open Access This article is distributed under the terms of the Creative Commons Attribution 4.0 International License (http://creativecommons.org/licenses/by/4.0/), which permits unrestricted use, distribution, and 
mGluR5 may also link $A \beta$ pathology to tau pathology in $\mathrm{AD}$ [12]. Complexes of $\mathrm{A} \beta \mathrm{o}$ and $\operatorname{PrP}^{\mathrm{c}}$ create a hydrogel phase that recruits mGluR5 [13], leading to activation of the tyrosine kinase Fyn [10]. This activation of Fyn leads to downstream tau phosphorylation [14]. Furthermore, functional tau is required for postsynaptic targeting of Fyn and subsequent excitotoxicity mediated by NMDA receptors [15]. The absence of functional tau prevents memory deficits and premature death in transgenic APP23 mice that develop A $\beta$ plaques [15].

Recognition of mGluR5 as a mediator of AD pathology and a potentially important therapeutic target [16] has stimulated the investigation of mGluR5 expression and receptor binding in AD models. Two studies have measured mGluR5 changes in mouse models of AD using positron emission tomography (PET). Fang et al. investigated mGluR5 in AßPP transgenic mice (tg-ArcSwe) using $\left[{ }^{11} \mathrm{C}\right] \mathrm{ABP} 688$-PET and reported no difference in binding compared to wild-type mice [17]. However, mGluR5 protein levels were increased in tg-ArcSwe mice when assessed with immunoblot. In a similar study, Lee et al. measured mGluR5 density in 5xFAD mice using $\left[{ }^{18}\right.$ F]FPEB-PET and immunoblot and observed lower mGluR5 binding and protein levels in the hippocampus and striatum compared to wild-type mice [18]. To our knowledge, no previous studies have investigated changes in mGluR5 receptor binding in living humans with AD.

In the present study, we utilized the PET radioligand $\left[{ }^{18} \mathrm{~F}\right] \mathrm{FPEB}$ to investigate mGluR5 binding in AD. To maximize statistical power in the setting of multiple regional comparisons, in our primary analyses, we focused on the hippocampus. This decision was based on postmortem [19, 20] and in vivo [21] evidence of early synaptic loss in this region in $\mathrm{AD}$, as well as mGluR5 reductions in AD model mice [18]. We also examined a composite association cortical region, given the evidence for selective vulnerability of association cortex in $\mathrm{AD}$ $[22,23]$. We hypothesized that mGluR5 binding in the hippocampus and association cortex would be reduced in $\mathrm{AD}$ compared to $\mathrm{CN}$ participants. Further exploratory analyses were conducted to determine whether mGluR5 binding was reduced in a wider range of regions. Finally, we examined the associations between mGluR5 binding in the hippocampus or association cortex with episodic memory performance and global function.

\section{Methods}

\section{Study participants and design}

Participants between 55 and 85 years old underwent a screening diagnostic evaluation to ensure eligibility. Individuals with $\mathrm{AD}$ dementia were required to meet diagnostic criteria for probable dementia due to $\mathrm{AD}$ according to the National Institute on Aging-
Alzheimer's Association [24], have a Clinical Dementia Rating (CDR) score of 0.5 to 1.0 points, and a MiniMental Status Examination (MMSE) score of 16 to 26 points, inclusive. Participants with MCI were required to meet research diagnostic criteria for amnestic MCI [25], have a CDR score of 0.5 points, and a MMSE score of 24 to 30 points, inclusive. Both participants with AD dementia and MCI were required to have impaired episodic memory as evidenced by a Logical Memory II (LMII) score of 1.5 standard deviations below an education-adjusted norm. Participants who were cognitively normal were required to have a CDR score of 0 , a MMSE score greater than 26, and a normal educationadjusted LMII score. The Rey Auditory Verbal Learning Test (RAVLT) was also administered to generate an episodic memory score. All participants received a PET scan with $\left[{ }^{11} \mathrm{C}\right]$ Pittsburgh Compound $\mathrm{B}\left(\left[{ }^{11} \mathrm{C}\right] \mathrm{PiB}\right)$ to determine the presence of brain amyloid- $\beta$ accumulation. The $\left[{ }^{11} \mathrm{C}\right] \mathrm{PiB}$ PET scan was considered positive if both visual and quantitative criteria were met. Visual criteria entailed consensus of 2 experienced readers (APM and $\mathrm{M}-\mathrm{KC})$, and quantitative criteria required a $\left[{ }^{11} \mathrm{C}\right] \mathrm{PiB}$ cerebral-to-cerebellar distribution volume ratio $(D V R)$ of 1.40 or more in at least $1 \mathrm{AD}$-affected region of interest (ROI) [26]. The study protocol was approved by the Yale University Human Investigation Committee and Radiation Safety Committee. All participants provided written informed consent prior to participating in the study.

\section{Magnetic resonance imaging}

Magnetic resonance imaging (MRI) was performed on a 3T Trio (Siemens Medical Systems, Erlangen, Germany) with a circularly polarized head coil. MRI acquisition consisted of a Sag 3D magnetization-prepared rapid gradient-echo (MPRAGE) sequence with 3.34-msec echo time, 2500-msec repetition time, 1100-msec inversion time, $7^{\circ}$ flip angle, and $180 \mathrm{~Hz} /$ pixel bandwidth. Images are $256 \times 256 \times 176$ with a pixel size of $0.98 \times$ $0.98 \times 1.0 \mathrm{~mm}$. The MRI ensured that patients did not show evidence of infection, infarction, or other brain lesions. In addition, the MRI was used to define anatomy, to evaluate atrophy, and to perform partial volume correction $(\mathrm{PVC})$.

\section{Positron emission tomography Acquisition and reconstruction}

PET scans were performed on the HRRT (207 slices, resolution $<3 \mathrm{~mm}$ full width half maximum), the highest resolution human PET scanner [27]. List-mode data were reconstructed using the MOLAR algorithm [28] with event-by-event motion correction based on an optical detector (Vicra, NDI Systems, Waterloo, Canada) [29]. 
Dynamic $\left[{ }^{11} \mathrm{C}\right] \mathrm{PiB}$ scans were acquired for $90 \mathrm{~min}$ following administration of up to $555 \mathrm{MBq}$ of tracer [30]. Dynamic $\left[{ }^{18} \mathrm{~F}\right] \mathrm{FPEB}$ scans were acquired for $60 \mathrm{~min}$, starting at $60 \mathrm{~min}$ after the initial administration of up to $185 \mathrm{MBq}$ of tracer using a bolus/infusion method $\left(K_{\mathrm{bol}}=190 \mathrm{~min}\right)$ [31].

\section{Image co-registration and MRI segmentation}

Software motion correction was applied to the dynamic PET images using a mutual-information algorithm (FSLFLIRT) to perform frame-by-frame registration to a summed image (60-70 min). A summed motion corrected PET image was registered to the participant's MRI. The individual's MRI was nonlinearly registered to a template MRI to obtain regions of interest (ROIs) defined in the automated anatomical labeling (AAL) template [32]. A full description of the ROIs can be found in Additional file 1. Transformations were performed with Bioimagesuite (version 2.5; www.bioimagesuite.com). MR images were segmented into gray matter (GM), white matter (WM), and cerebrospinal fluid (CSF) using FAST-FMRIB's Automated Segmentation Tool (The Analysis Group, FMRIB, Oxford, UK). GM masking was performed by restricting ROIs using the GM segmentation mask.

\section{Partial volume correction}

PVC was performed using the Müller-Gärtner approach [33], according to previously described procedures [30]. Binary mask images of GM and WM were smoothed to the system resolution $(\sim 3 \mathrm{~mm})$. For each dynamic PET frame, GM voxels were corrected for spill-in and spillout of activity, assuming activity in CSF was zero and WM activity was uniform and was estimated from each image time frame.

\section{Tracer kinetic modeling}

For $\left[{ }^{11} \mathrm{C}\right] \mathrm{PiB}$ image analysis, parametric images of binding potential $\left(B P_{\mathrm{ND}}\right)$, the ratio at equilibrium of specifically bound radioligand to that of nondisplaceable radioligand in tissue [34], were generated using SRTM2 [35] with whole cerebellum as the reference region. $B P_{\mathrm{ND}}$ was calculated so that a value of 0 reflects no specific binding, i.e., tracer uptake no greater than that in the reference region. This is directly related to the $D V R$ reported by other investigators [26], in that $D V R=B P_{\mathrm{ND}}+1$.

For $\left[{ }^{18} \mathrm{~F}\right] \mathrm{FPEB}$ image analysis, parametric images of $B P_{\mathrm{ND}}$ were generated using equilibrium methods [36] with PET data collected from 90 to $120 \mathrm{~min}$ postinjection and whole cerebellum reference region [31,37]. Three sets of $B P_{\mathrm{ND}}$ values were extracted: (1) uncorrected $B P_{\mathrm{ND}}$ using the full AAL region, (2) uncorrected $B P_{\mathrm{ND}}$ from the AAL region masked only to include GM voxels, and (3) PVC $B P_{\mathrm{ND}}$, again with GM masking. We have previously evaluated a bolus plus constant infusion paradigm for equilibrium modeling of both the distribution volume $\left(V_{\mathrm{T}}\right)$ and $B P_{\mathrm{ND}}$ for $\left[{ }^{18} \mathrm{~F}\right] \mathrm{FPEB}[31,38]$ and demonstrated excellent test-retest reproducibility for both parameters [31]. Although a validated reference region is not available for mGluR5-specific radioligands [39], the estimation of $B P_{\mathrm{ND}}$ using a region with a small amount of specific binding may be useful with certain assumptions and limitations (see the "Discussion" section). One such assumption is that the specific binding in the reference region does not differ between diagnostic groups. In support of this assumption, we also compared $V_{\mathrm{T}}$ in whole cerebellum between our $\mathrm{AD}$ and $\mathrm{CN}$ groups. $V_{\mathrm{T}}$ was calculated as the tissue-to-plasma radioactivity ratio at equilibrium (90$120 \mathrm{~min}$ postinjection) and reflects total uptake (specific plus nonspecific binding).

\section{Whole brain PET and volumetric MRI analyses}

Cortical reconstruction and volumetric segmentation were performed using Freesurfer (version 6.0, http:// surfer.nmr.mhg.harvard.edu/) [40]. GM volume was normalized using estimated total intracranial volume [41]. For $\left[{ }^{18} \mathrm{~F}\right]$ FPEB image analysis, Freesurfer was used to coregister the parametric $B P_{\mathrm{ND}}$ image to the MRI for each subject. $\left[{ }^{18} \mathrm{~F}\right] \mathrm{FPEB} B P_{\mathrm{ND}}$ images were then sampled to the cortical surface and spatially smoothed using a 10 mm FWHM gaussian kernal.

\section{Statistical analyses}

Statistical analyses were performed using SPSS version 21.0 (IBM Corp.) or Matlab R2015a Statistics Toolbox (Mathworks, Inc.). Primary analyses utilized linear mixed models to compare mGluR5 binding $\left(B P_{\mathrm{ND}}\right)$ in the hippocampus and composite association cortex (withinparticipant factor) between $\mathrm{AD}$ and $\mathrm{CN}$ groups. The best-fitting variance-covariance structure, as determined by Bayesian information criterion, was compound symmetry. Secondary analyses utilized a similar model with exploratory regions listed in Table 2. Post hoc comparisons utilized unpaired $t$ tests. To evaluate the contribution of GM tissue loss to mGluR5 reductions in $A D$, group differences in regional $B P_{\mathrm{ND}}$ after $\mathrm{GM}$ masking or PVC, as well as in regional GM volume, were also assessed using unpaired $t$ tests. Additional exploratory analyses examined the relationships between hippocampal or association cortical $B P_{\mathrm{ND}}$ and episodic memory (average $z$-scores for LMII and RAVLT) and global function (CDR sum of boxes [CDR-SB]) in the combined sample with Pearson's correlation. Tests were two-tailed and used $p<0.05$ as a threshold for significance. Vertexwise, whole cortical analyses were performed with general linear models using Freesurfer. Permutation was used to correct for multiple comparisons. The clusterforming threshold was $p<0.01$, and the cluster-wise threshold was $p<0.05$. 


\section{Results}

\section{Participant characteristics}

The study sample consisted of 31 participants-16 with amnestic MCI due to AD or mild AD dementia and 15 who were CN. Diagnostic groups were well balanced for age, sex, and education, and both groups were highly educated (Table 1). AD participants had clinical characteristics typical of amnestic MCI and mild AD dementia with $\mathrm{MMSE}=24.6 \pm 4.3$ and CDR-global $=0.72 \pm 0.26$.

\section{mGluR5 binding in Alzheimer's disease compared to cognitively normal participants}

All participants received one injection of $\left[{ }^{18} \mathrm{~F}\right] \mathrm{FPEB}$ $(172 \pm 21 \mathrm{MBq})$ with no significant difference in radioactivity (unpaired $t$ test, $p=0.132$ ) or mass dose (unpaired $t$ test, $p=0.412$ ) between groups. We observed no difference in whole cerebellar $V_{\mathrm{T}}$ from 90 to 120 min postinjection between $\mathrm{AD}(9.3 \pm 1.8)$ and $\mathrm{CN}(8.6 \pm 2.2)$ groups (unpaired $t$ test, $p=0.309$ ), supporting the use of cerebellum as the reference region in $B P_{\mathrm{ND}}$ calculations. Therefore, analyses were performed using parametric images normalized to whole cerebellum at equilibrium. Representative images of mGluR5 binding $\left(B P_{\mathrm{ND}}\right)$ indicate receptor availability throughout the cortex and in subcortical structures (Fig. 1a). Linear mixed model analysis, including group (CN, AD), region (hippocampus, association cortex), and the group $\times$ region interaction as predictors, demonstrated a significant effect of group $(F(1,31)=7.4$, $p=0.011)$ and group $\times$ region $(F(1,31)=9.2, p=0.0049)$ on $B P_{\mathrm{ND}}$. Consistent with our hypothesis, we found a significant reduction (43\%) in $B P_{\mathrm{ND}}$ in the hippocampus in $\mathrm{AD}(0.76 \pm 0.41)$ compared to $\mathrm{CN}(1.34 \pm 0.58)$ participants $(p=0.003$, unpaired $t$ test, Fig. $1 \mathrm{~b})$. However, we observed only a nonsignificant trend in mGluR 5 binding in the association cortex between $\mathrm{AD}(1.57 \pm 0.25)$ and $\mathrm{CN}(1.86 \pm 0.63)$ participants $(p=0.093$, unpaired $t$ test, Fig. 1c).

Table 1 Participant characteristics and test results

\begin{tabular}{lll}
\hline & Cognitively normal & Alzheimer's disease \\
\hline Participants $(n)$ & 15 & 16 (mild dementia, 8; MCl, 8) \\
Sex (M/F) & $6 / 9$ & $7 / 9$ \\
Age (years) & $71.5(8.4)(59-84)$ & $73.1(5.7)(63-82)$ \\
Education (years) & $17.1(2.3)(12-20)$ & $16.7(2.5)(12-20)$ \\
CDR-global & $0(0)$ & $0.72(0.26)(0.5-1)$ \\
CDR-SB & $0(0)$ & $3.9(2.2)(0.5-9.0)$ \\
MMSE & $29.2(1.2)(27-30)$ & $24.6(4.3)(17-29)$ \\
LMII & $13.7(3.8)(5-19)$ & $1.9(2.5)(0-7)$ \\
RAVLT-delay & $11.7(2.9)(4-15)$ & $1.6(2.5)(0-7)$
\end{tabular}

Data are mean (SD) (range). CDR-global Clinical Dementia Rating global score, CDR-SB Clinical Dementia Rating sum of boxes, MMSE Mini-Mental State Examination, LMII Logical Memory II score, RAVLT Rey Auditory Verbal Learning Test
A secondary linear mixed model analysis explored the effect of diagnostic group ( $\mathrm{AD}, \mathrm{CN})$ on mGluR5 binding $\left(B P_{\mathrm{ND}}\right)$ in a wider range of brain regions (Table 2$)$. This analysis yielded a significant effect of group $\times$ region $(F$ $(11,82)=2.38, p=0.013)$, but not group $(F(1,29)=3.50$, $p=0.072)$. Post hoc analyses showed significant reductions of mGluR5 $\left(B P_{\mathrm{ND}}\right)$ in the entorhinal cortex $(34 \%$ reduction, $p=0.002)$ and parahippocampal gyrus $(26 \%$ reduction, $p=0.012$ ) of AD participants (Table 2, unpaired $t$ test, uncorrected for multiple comparisons).

\section{Corrections for gray matter atrophy and partial volume effect}

To evaluate the contribution of GM tissue loss to mGluR5 reductions in $\mathrm{AD}$, we performed GM masking and PVC (Table 3). Hippocampal mGluR5 binding remained significantly lower in $\mathrm{AD}$ than in $\mathrm{CN}$ participants with $\mathrm{GM}$ masking $\left(B P_{\mathrm{ND}}=1.30 \pm 0.33\right.$ vs. $1.78 \pm$ $0.61, p=0.011)$ and PVC $\left(B P_{\mathrm{ND}}=2.19 \pm 0.45\right.$ vs. $2.69 \pm$ $0.88, p=0.0499)$. For the exploratory regional analyses, the reduction in mGluR5 remained significant after GM masking in the entorhinal cortex, but not in the parahippocampal gyrus. However, neither region retained significance after PVC (Table 3). This stepwise reduction in effect size with application of GM masking and PVC is consistent with both a dilution effect (i.e., as atrophy increases, GM volume within a region decreases) and a partial volume effect of GM atrophy on mGluR5 binding. To further elucidate these effects, we also performed a volumetric MRI analysis to assess GM volume differences between groups. This analysis demonstrated significant reductions in GM volume in the AD participants that were largest in the hippocampus and entorhinal cortex, but also present in the composite association cortex, parahippocampal gyrus, lateral temporal cortex, posterior cingulum, and occipital cortex (Additional file 1: Table S1).

\section{Association between mGluR5 binding and episodic memory performance and global function}

Pearson's correlations were performed to assess the relationship between mGluR5 binding and clinical assessments. Statistically significant correlations were found between hippocampal $B P_{\mathrm{ND}}$ and CDR-SB $(r=-0.53$, $p=0.002)$ and episodic memory performance $(r=0.40$, $p=0.027$; Fig. 2). No significant correlations were observed between association cortical $B P_{\mathrm{ND}}$ and CDR-SB $(r=-0.27, p=0.143)$ or episodic memory performance $(r=0.14, p=0.451)$.

\section{Whole brain analyses of mGluR5 binding}

Further exploratory analyses were performed to compare mGluR5 binding in $\mathrm{AD}$ and $\mathrm{CN}$ participants for both the whole cortex (surface-based approach) and all 

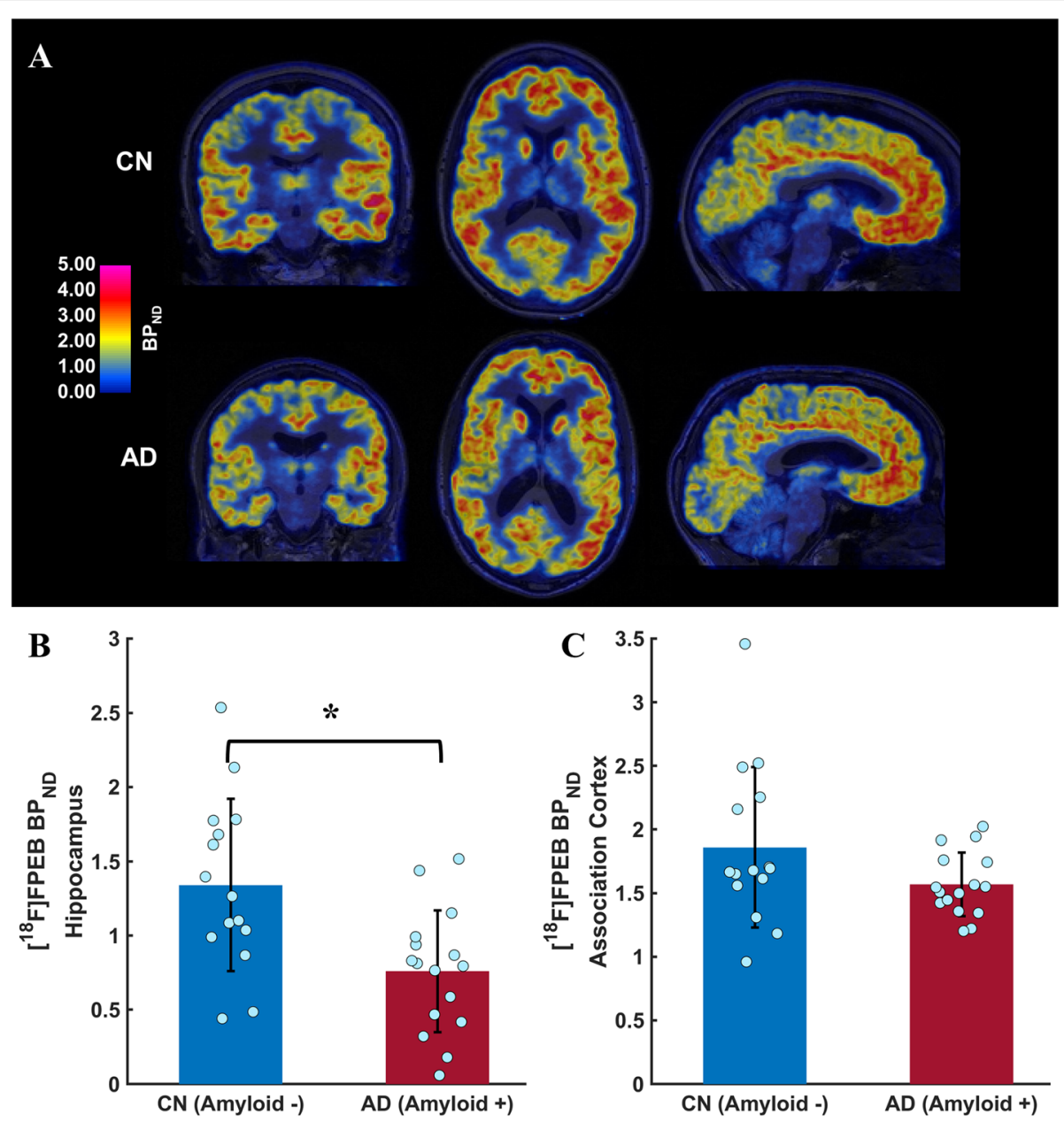

Fig. 1 mGluR binding $\left(\left[^{18} \mathrm{~F}\right]\right.$ FPEB $\left.B P_{\mathrm{ND}}\right)$ in $A D$ and $C N$ participants measured with $\left[{ }^{18} \mathrm{~F}\right]$ FPEB-PET. a Coronial, axial, and sagittal images of $\left[{ }^{18} \mathrm{~F}\right] \mathrm{FPEB}$ parametric PET ( $B P_{\mathrm{ND}}$ ) overlaid with T1 MRI scans in a representative CN (top row) and AD (bottom row) participant. The pseudocolor in PET images represents the intensity of $\left[{ }^{18} \mathrm{~F}\right] \mathrm{FPEB}$ binding $\left(B P_{\mathrm{ND}}\right)$. Reductions of $\left[{ }^{18} \mathrm{~F}\right] \mathrm{FPEB}$ binding are most noticeable in the medial temporal lobe including hippocampus in the AD compared to the CN participants. However, mGluR5 binding appears to be lower in most cortical regions. Comparison of mGluR5 binding in the hippocampus (b) and association cortex (c) between AD and CN participants. AD participants-compared to CN participants-demonstrated significantly lower overall mGluR5 binding $(F(1,31)=7.4, p=0.011)$. In addition, there was a significant diagnostic group $\times$ region interaction $(F(1,31)=9.2, p=0.0049)$. Post hoc analyses revealed that hippocampal $m G l u R 5$ binding $(p=0.003, t$ test), but not association cortical mGluR5 binding $(p=0.093)$, was reduced in AD participants. Error bars represent standard deviations. $B P_{\mathrm{ND}}$, binding potential; $\mathrm{CN}$, cognitively normal; AD, Alzheimer's disease. ${ }^{*} p<.05$

FreeSurfer Desikan-Killiany regions. For the surface-based analysis, there were no significant differences between $\mathrm{AD}$ and $\mathrm{CN}$ groups when a cluster-wise correction for multiple comparisons was applied. In an uncorrected surfacebased analysis, the cortical pattern of mGluR 5 binding in AD included significant reductions in the entorhinal cortex and posterior cingulum. There were also clusters of reduced signal throughout the cortices more broadly (Fig. 3, Additional file 1: Table S2).

For the analysis of all FreeSurfer regions, the effect size (Cohen's $d$ ) to detect a difference in $B P_{\mathrm{ND}}$ between $\mathrm{AD}$ and $\mathrm{CN}$ groups was calculated (Additional file 1: Figure S1). Consistent with the primary regional analyses, the largest effect sizes were found in the medial temporal lobe. Additional file 1 :
Table S3 presents group differences (unpaired $t$ tests) for all ROIs included in Additional file 1: Figure S1.

\section{Discussion}

We used PET to investigate $\left[{ }^{18} \mathrm{~F}\right] \mathrm{FPEB}$ binding $\left(B P_{\mathrm{ND}}\right)$ in early $\mathrm{AD}$ and observed a significant $43 \%$ reduction of mGluR5 availability in hippocampus but only a nonsignificant trend in a composite association cortical region. Exploratory analyses in a wider range of ROIs also suggested lower mGluR5 binding in the entorhinal cortex and parahippocampal gyrus. Reduction in mGluR5 availability in the hippocampus, but not entorhinal cortex or parahippocampal gyrus, remained significant after corrections for GM atrophy and partial volume effects. Additional exploratory analyses 
Table 2 mGluR5 binding $\left.\left({ }^{18} \mathrm{~F}\right] \mathrm{FPEB} B P_{\mathrm{ND}}\right)$ in exploratory brain regions of interest

\begin{tabular}{llll}
\hline Exploratory regions & Cognitively normal & Alzheimer's disease & $p$ \\
& Mean $B P_{\text {ND }}(S D)$ & Mean $B P_{\text {ND }}($ SD) & 0.155 \\
Prefrontal cortex & $1.89(0.65)$ & $1.64(0.25)$ & $1.07(0.45)$ \\
Entorhinal cortex & $1.62(0.46)$ & $1.13(0.32)$ & $0.002^{*}$ \\
Parahippocampal gyrus & $1.52(0.48)$ & $1.59(0.27)$ & $0.012^{*}$ \\
Lateral temporal cortex & $1.94(0.64)$ & $1.50(0.29)$ & 0.060 \\
Lateral parietal cortex & $1.80(0.59)$ & $0.79(0.25)$ & 0.077 \\
Posterior cingulum & $0.99(0.61)$ & $1.50(0.26)$ & 0.230 \\
Precuneus & $1.77(0.57)$ & $1.44(0.21)$ & 0.094 \\
Occipital cortex & $1.67(0.53)$ & $1.07(0.51)$ & 0.113 \\
Caudate & $1.26(0.72)$ & $1.96(0.30)$ & 0.391 \\
Putamen & $2.16(0.77)$ & $0.64(0.25)$ & 0.326 \\
Thalamus & $0.90(0.50)$ & 0.080 \\
\hline
\end{tabular}

Data are mean (SD). $B P_{N D}$ binding potential of $\left[{ }^{18} \mathrm{~F}\right] \mathrm{FPEB}$ in regions of interest. Cognitively normal $(n=15)$, Alzheimer's disease $(n=16) . p$ values are for post hoc two-tailed, unpaired $t$ tests (uncorrected for multiplicity) performed after a linear mixed model analysis of $B P_{\mathrm{ND}}$ in multiple regions (within-subject factor) between $\mathrm{CN}$ and $\mathrm{AD}$ diagnostic groups ${ }^{*} p<.05$

suggested that hippocampal mGluR5 binding was associated with episodic memory performance and inversely associated with global function (CDR-SB) in the overall sample.

\section{Comparison with AD model mouse and postmortem human studies}

This is the first investigation of mGluR5 availability in living AD subjects. Previous studies of mGluR5 expression have been limited to mouse models of $\mathrm{AD}$ and a single small postmortem report. Fang et al. investigated changes in mGluR5 expression in A $\beta P P$ transgenic mice (tg-ArcSwe) with ex vivo immunoblotting and in vivo $\left[{ }^{11} \mathrm{C}\right] \mathrm{ABP} 688$-PET imaging. Immunoblot assays showed that brain mGluR5 levels tended to be upregulated in tg-ArcSwe mice compared with wild-type mice, although these changes were not discernible with PET [17]. By contrast, Lee et al. measured mGluR5

Table 3 mGluR5 binding $\left(\left[{ }^{18} \mathrm{~F}\right] \mathrm{FPEB} B P_{\mathrm{ND}}\right)$ in brain regions of interest

\begin{tabular}{|c|c|c|c|c|c|c|}
\hline & \multicolumn{3}{|c|}{$B P_{\mathrm{ND}}$ - gray matter masked } & \multicolumn{3}{|c|}{$B P_{N D}$ - partial volume corrected } \\
\hline & $\overline{C N}$, mean $(\mathrm{SD})$ & $A D$, mean $(S D)$ & $p$ & $\mathrm{CN}$, mean $(\mathrm{SD})$ & $A D$, mean $(S D)$ & $p$ \\
\hline \multicolumn{7}{|l|}{ Primary region } \\
\hline Hippocampus & $1.78(0.61)$ & $1.30(0.33)$ & $0.011^{*}$ & $2.69(0.88)$ & $2.19(0.45)$ & $0.0499 *$ \\
\hline Composite association cortex & $2.38(0.76)$ & $2.04(0.29)$ & 0.111 & $4.39(1.30)$ & $3.99(0.47)$ & 0.258 \\
\hline \multicolumn{7}{|l|}{ Exploratory regions } \\
\hline Prefrontal cortex & $2.43(0.78)$ & $2.15(0.29)$ & 0.197 & $4.48(1.34)$ & $4.10(0.49)$ & 0.310 \\
\hline Entorhinal cortex & $1.99(0.72)$ & $1.52(0.43)$ & $0.034^{*}$ & $3.18(1.18)$ & $2.69(0.54)$ & 0.144 \\
\hline Parahippocampal gyrus & $1.96(0.69)$ & $1.58(0.33)$ & 0.052 & $3.26(1.13)$ & $2.86(0.44)$ & 0.199 \\
\hline Lateral temporal cortex & $2.43(0.81)$ & $2.03(0.31)$ & 0.075 & $4.24(1.34)$ & $3.78(0.45)$ & 0.204 \\
\hline Lateral parietal cortex & $2.32(0.72)$ & $1.97(0.31)$ & 0.091 & $4.44(1.26)$ & $4.01(0.52)$ & 0.211 \\
\hline Posterior cingulum & $1.65(0.64)$ & $1.42(0.30)$ & 0.219 & $3.23(1.05)$ & $3.01(0.45)$ & 0.448 \\
\hline Precuneus & $2.15(0.66)$ & $1.82(0.27)$ & 0.079 & $4.08(1.16)$ & $3.71(0.47)$ & 0.249 \\
\hline Occipital cortex & $2.02(0.59)$ & $1.77(0.25)$ & 0.120 & $3.82(1.03)$ & $3.57(0.41)$ & 0.388 \\
\hline Caudate & $2.17(0.86)$ & $1.98(0.42)$ & 0.439 & $3.41(1.26)$ & $3.14(0.46)$ & 0.427 \\
\hline Putamen & $2.79(0.91)$ & $2.57(0.35)$ & 0.381 & $4.44(1.37)$ & $4.19(0.64)$ & 0.514 \\
\hline Pallidum & $0.96(0.41)$ & $0.81(0.42)$ & 0.312 & $2.50(1.18)$ & $2.30(0.83)$ & 0.599 \\
\hline Thalamus & $1.38(0.61)$ & $1.12(0.27)$ & 0.118 & $2.40(0.91)$ & $2.04(0.41)$ & 0.162 \\
\hline
\end{tabular}

Data are mean (SD). $B P_{N D}$ binding potential of $\left[{ }^{18} \mathrm{~F}\right] \mathrm{FPEB}$ in regions of interest, $C N$ cognitively normal $(n=15)$, AD Alzheimer's disease $(n=16) . p$ values are for post hoc two-tailed, unpaired $t$ tests (uncorrected for multiplicity) performed after a linear mixed model analysis of $B P_{\mathrm{ND}}$ in multiple regions (within-subject factor) between $\mathrm{CN}$ and $\mathrm{AD}$ diagnostic groups 

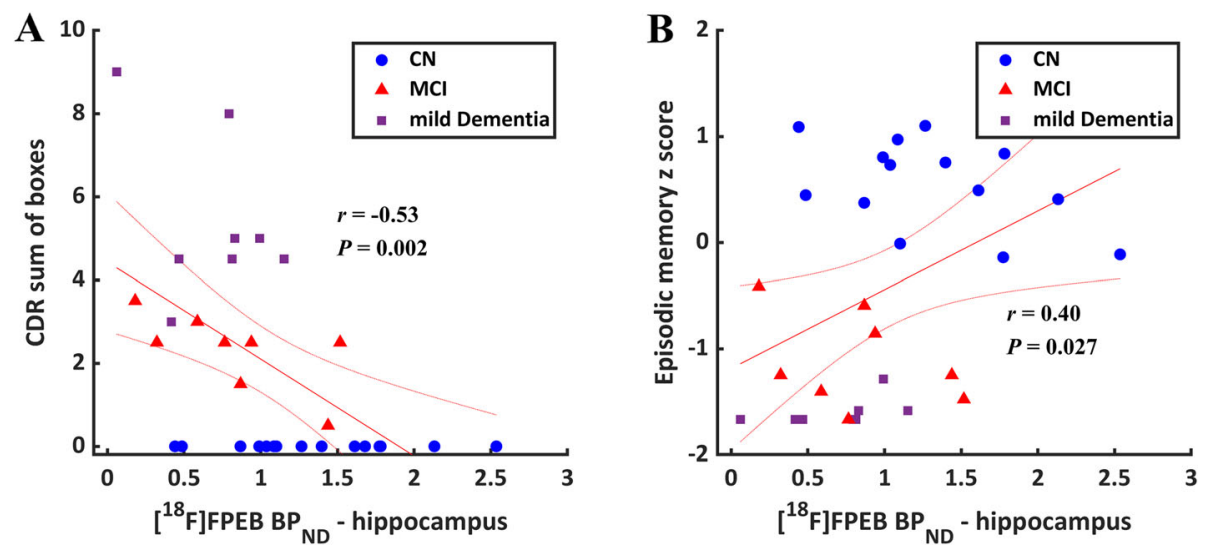

Fig. 2 Association of mGluR5 binding $\left.\left({ }^{18} \mathrm{~F}\right] \mathrm{FPEB} B P_{\mathrm{ND}}\right)$ in the hippocampus with Clinical Dementia Rating (CDR) sum of boxes and episodic memory. Reduced hippocampal mGluR5 binding was associated with more severe disease $(r=-0.53, p=0.002)$ measured by CDR sum of boxes (a) and lower composite episodic memory scores (b) $(r=0.40, p=0.027)$ in the overall sample. Episodic memory performance is the average of $z-$ scores for CVLT free delayed recall and Logical Memory II. The figure displays linear regression line with its 95\% confidence interval. CDR, Clinical Dementia Rating

density in 5xFAD mice using $\left[{ }^{18} \mathrm{~F}\right] \mathrm{FPEB}-\mathrm{PET}$ and immunoblot and observed lower mGluR5 binding and protein levels in the hippocampus and striatum compared to wild-type mice [18]. The reasons for these divergent findings in mouse models of $\mathrm{AD}$ are unclear. However, 5xFAD mice recapitulate more features of $\mathrm{AD}$, including loss of neurons and a reduction of several synaptic markers [42], which may explain the greater similarity to our results with $\left[{ }^{18} \mathrm{~F}\right]$ FPEB-PET in human $\mathrm{AD}$. The only postmortem study of mGluR5 binding in $\mathrm{AD}$ by Müller Herde et al. [43] utilized $\left[{ }^{18} \mathrm{~F}\right] \mathrm{PSS} 232$ autoradiography and reported increases in the frontal cortex (5.2fold) and hippocampus (2.5-fold) in 6 patients with severe $\mathrm{AD}$ compared to 6 controls. The authors speculate that neuroinflammation may lead to mGluR5 upregulation in severe
$\mathrm{AD}$ and note that these results may not apply to early-stage $\mathrm{AD}$, which may indeed explain the discrepancy with our results using $\left[{ }^{18} \mathrm{~F}\right]$ FPEB-PET. However, further postmortem and in vivo research at different stages of $\mathrm{AD}$ will be necessary to elucidate these issues.

\section{Relevance for $A D$ pathogenesis}

The significance of reduced hippocampal $\left[{ }^{18} \mathrm{~F}\right] \mathrm{FPEB}$ binding in early $\mathrm{AD}$ is unclear. Hippocampal reductions in mGluR5 may simply be the product of nonspecific synaptic loss, which would explain the similarity of these results (43\% reduction in hippocampal $B P_{\mathrm{ND}}$ ) with our recent findings with the synaptic PET tracer $\left[{ }^{11} \mathrm{C}\right] \mathrm{UCB}-\mathrm{J}$ in a comparable early $\mathrm{AD}$ sample [21]. That study

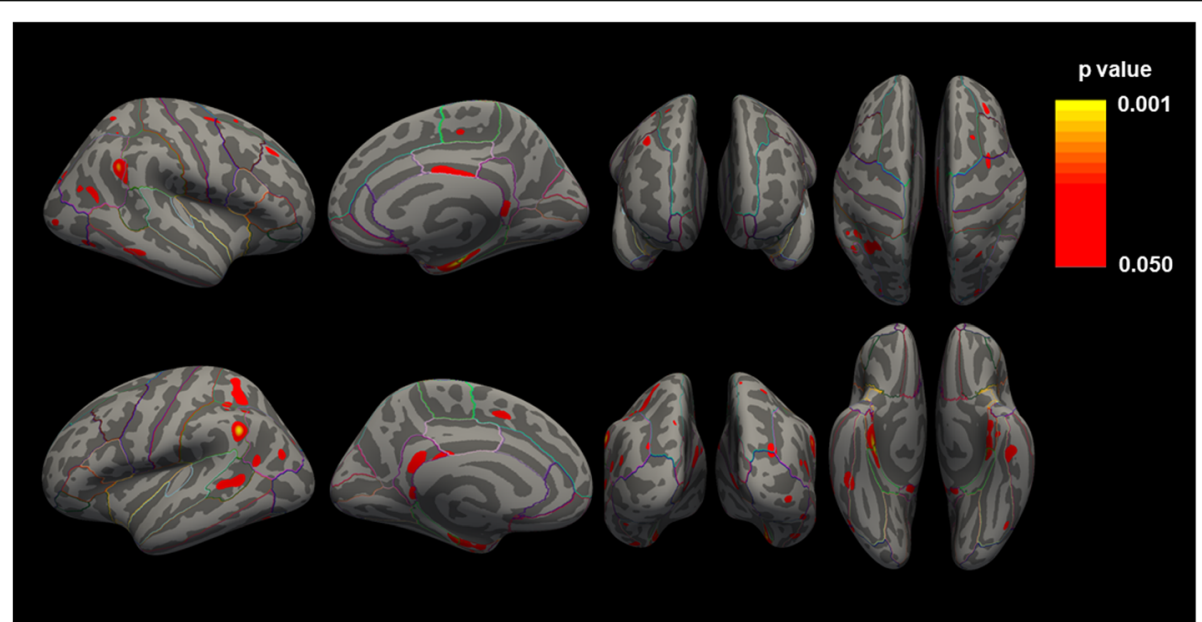

Fig. 3 Whole cortex comparison of mGluR5 binding ( $\left.\left[{ }^{18} \mathrm{~F}\right] \mathrm{FPEB} B P_{\mathrm{ND}}\right)$ between AD and CN groups. $p$ values are for vertex-wise comparisons between $\mathrm{AD}$ and $\mathrm{CN}$ groups uncorrected for multiple comparisons and thresholded at $p<.05$. Significant vertices are represented in pseudocolor. All displayed clusters are for the contrast $C N>A D$. $B P_{N D}$, binding potential; $C N$, cognitively normal; $A D$, Alzheimer's disease 
demonstrated a $41 \%$ reduction in hippocampal $B P_{\mathrm{ND}}$, consistent with postmortem reports of hippocampal synaptic loss in MCI and mild AD [19, 20]. Alternatively, the presence of mGluR5 may influence the regional pattern of synaptic loss, given the evidence for involvement of this receptor in AD pathogenesis. mGluR5 has been hypothesized to mediate $\mathrm{A} \beta \mathrm{o}$ synaptotoxicity by a number of mechanisms, including promoting the clustering of $A \beta o$ as an extracellular scaffold for mGluR5 [9] and serving as a co-receptor for $\mathrm{A} \beta$ o bound to $\operatorname{PrP}^{\mathrm{C}}$ for postsynaptic activation of the tyrosine kinase Fyn $[11,44]$. If $\mathrm{A} \beta \mathrm{o}$ synaptotoxicity occurs preferentially at mGluR5 sites, then this might also account for the synaptic pattern of mGluR5 reductions in the present study. Multitracer PET imaging studies with $\left[{ }^{18} \mathrm{~F}\right] \mathrm{FPEB}$ and $\left[{ }^{11} \mathrm{C}\right]$ UCB-J may be able to dissociate the regional pattern of mGluR5 and synaptic losses in early AD.

\section{Corrections for brain atrophy}

We have presented mGluR5 binding results for $\left[{ }^{18}\right.$ F]FPEB-PET both with and without correction for AD-related decreases in regional brain volumes. We calculated the $B P_{\mathrm{ND}}$ for AAL-derived ROIs and repeated this calculation using a GM mask [30]. Finally, we performed PVC with the Müller-Gärtner algorithm to correct for GM signal loss (spill-out) due to atrophy [30, 33]. PVC typically has its greatest impact in those ROIs with large differences in GM volume between $\mathrm{AD}$ and $\mathrm{CN}$ groups (Additional file 1: Table S1) where spill-out could falsely lower $B P_{\mathrm{ND}}$. As expected, values of $B P_{\mathrm{ND}}$ increased with application of these correction methods (Table 2 and Table 3), but group differences in hippocampal mGluR5 binding remained significant-albeit with decreased magnitude. Our results suggest that lower hippocampal mGluR5 binding in AD is driven partly by a loss of GM volume but that a decrease in receptor density is also present in the remaining tissue. Among the outcome measures presented, the optimal one may depend on the particular purpose. Uncorrected analyses have greater sensitivity when mGluR5 imaging is utilized as a biomarker of disease presence or progression and may introduce less measurement error. This measure also summarizes the net loss of mGluR5, i.e., a combination of tissue loss and loss of mGluR5 in the remaining tissue. Corrections for GM loss and partial volume effects are better suited to determine group differences in receptor concentrations and may permit comparison to in vitro studies using animal models and postmortem human brain tissue.

\section{Assumptions and limitations of mGluR5 receptor quantification with $B P_{\mathrm{ND}}$}

In this study, we quantified $\left[{ }^{18} \mathrm{~F}\right] \mathrm{FPEB}$ binding to mGluR5 using $B P_{\mathrm{ND}}$ generated from equilibrium modeling [36] with whole cerebellum as the reference region. We have previously evaluated a bolus plus constant infusion paradigm for equilibrium modeling of $V_{\mathrm{T}}$ and $B P_{\mathrm{ND}}$ for $\left[{ }^{18} \mathrm{~F}\right]$ FPEB $[31,37,38]$ and demonstrated excellent testretest reproducibility for both parameters [31]. A major strength of $B P_{\mathrm{ND}}$ over $V_{\mathrm{T}}$-particularly for an older, $\mathrm{AD}$ population-is that it does not require arterial or venous blood sampling and is less susceptible to errors in the input function $[28,40]$. The major limitation of $B P_{\mathrm{ND}}$ for mGluR5 quantification with $\left[{ }^{18} \mathrm{~F}\right] \mathrm{FPEB}$ is that it assumes a validated reference region with negligible specific binding. Although cerebellum is the region with the least mGluR5 specific binding, a small but measurable mGluR5 signal is observed in human cerebellum [33]. This will cause $B P_{\mathrm{ND}}$ values to be underestimated and the magnitude of percent group differences to be overestimated. Nonetheless, the estimation of $B P_{\mathrm{ND}}$ using a region with a small amount of specific binding may be useful with certain assumptionsin particular, that specific binding in the reference region does not differ between diagnostic groups. Importantly, we observed no significant difference in cerebellar $V_{\mathrm{T}}$ (reflecting specific plus nonspecific binding) between $\mathrm{AD}$ and $\mathrm{CN}$ groups.

\section{Conclusion}

We observed reduced hippocampal mGluR5 binding with $\left[{ }^{18} \mathrm{~F}\right] \mathrm{FPEB}-\mathrm{PET}$ in early $\mathrm{AD}$ compared to $\mathrm{CN}$ participants. Exploratory analyses suggested that these reductions may extend to other medial temporal lobe structures. Further study is needed to define the regional pattern and temporal course of mGluR5 alterations in $\mathrm{AD}$, as well as the associations with cognitive and functional status. Quantification of $\left[{ }^{18} \mathrm{~F}\right] \mathrm{FPEB}$ binding to mGluR5 in AD may expand our understanding of $A D$ pathogenesis and aid in the development of novel biomarkers and treatments.

\section{Supplementary information}

Supplementary information accompanies this paper at https://doi.org/10. 1186/s13195-020-0582-0.

\footnotetext{
Additional file 1: Supplemental Methods. Description of AAL regions use to construct composite ROls. Table S1. Gray Matter Volume $\left(\mathrm{cm}^{3}\right)$ in brain regions of interest. Gray matter volume comparison in $A D$ and $C N$ groups. Table S2A. Left hemisphere surface-based analysis of mGluR5 binding. List of freesurfer $\mathrm{ROI}$ group differences in the left hemisphere. Table S2B. Right hemisphere surface-based analysis of mGluR5 binding. List of freesurfer $\mathrm{ROI}$ group differences in the right hemisphere. Figure S1. Effect size maps of $\left[{ }^{18} \mathrm{~F}\right] \mathrm{FPEB}$ binding $\left(B P_{\mathrm{ND}}\right)$ to mGluR5 in $\mathrm{AD}$ compared to CN participants. Table S3. mGluR5 binding in all FreeSurfer regions.
}

Abbreviations

AAL: Automated anatomical labeling; AD: Alzheimer's disease; Aßo: Amyloid$\beta$ oligomer; tg-ArcSwe: ABPP transgenic mice; $B P_{\mathrm{ND}}$ : Binding potential; PiB: Pittsburgh Compound B; CDR: Clinical Dementia Rating; CN: Cognitively normal; CSF: Cerebrospinal fluid; DVR: Distribution volume ratio; GM: Gray matter; LMII: Logical Memory II; MCl: Mild cognitive impairment; 
mGluR5: Metabotropic glutamate subtype 5 receptor; MMSE: Mini-Mental Status Examination; MPRAGE: Magnetization-prepared rapid gradient-echo; MRI: Magnetic resonance imaging; PET: Positron emission tomography; PrPc: Cellular prion protein; PVC: Partial volume correction; RAVLT: Rey Auditory Verbal Learning Test; ROI: Region of interest; $V_{T}$ : Distribution volume; WM: White matter

\section{Acknowledgements}

We wish to thank staff of the Yale PET Center for their excellent technical assistance and Brent Vander Wyk, Ph.D., for his review of the statistical analysis plan.

\section{Authors' contributions}

APM, REC, SMS, and CHV contributed to the study concept and design. APM JWM, HRM, TAG, JEH, MKC, AS, NBN, KL, YH, REC, SMS, and CHV contributed to the acquisition, analysis, or interpretation of the data, as well as critical revision of the manuscript for important intellectual content. APM, REC, and $\mathrm{CHV}$ performed the statistical analysis. APM, REC, CHV, and SMS obtained the funding. APM, MKC, AS, NBN, KL, YH, REC, SMS, and CHV provided administrative, technical, or material support. All authors read and approved the final manuscript.

\section{Funding}

This research was supported by the National Institute on Aging (P50-AG047270 and K23-AG057784) and National Institute of Mental Health (R25-MH071584). The funding bodies had no role in the design of the study, data collection, analysis, interpretation, or writing of the manuscript.

\section{Availability of data and materials}

The datasets used and/or analyzed during the current study are not publicly available due to ongoing analysis and manuscript preparation but are available from the corresponding author on reasonable request.

\section{Ethics approval and consent to participate}

The study protocol was approved by the Yale University Human Investigation Committee and Radiation Safety Committee. All participants provided written informed consent prior to participating in the study.

\section{Consent for publication}

Not applicable

\section{Competing interests}

The authors declare that they have no competing interests.

\begin{abstract}
Author details
'Alzheimer's Disease Research Unit, Yale University School of Medicine, One Church Street, 8th Floor, New Haven, CT 06510, USA. ²Department of Psychiatry, Yale University School of Medicine, New Haven, CT, USA. ${ }^{3}$ Department of Neuroscience, Yale University School of Medicine, New Haven, CT, USA. ${ }^{4}$ Department of Neurology, Yale University School of Medicine, New Haven, CT, USA. ${ }^{5}$ Department of Radiology and Biomedical Imaging, Yale University School of Medicine, New Haven, CT, USA. ${ }^{6}$ CNNR Program, Yale University School of Medicine, 295 Congress Avenue, Ste 431-435, New Haven, CT, USA.
\end{abstract}

Received: 21 July 2019 Accepted: 5 January 2020

Published online: 18 January 2020

\section{References}

1. Awad H, Hubert GW, Smith Y, Levey Al, Conn PJ. Activation of metabotropic glutamate receptor 5 has direct excitatory effects and potentiates NMDA receptor currents in neurons of the subthalamic nucleus. J Neurosci. 2000; 20(21):7871-9.

2. Abushik PA, Niittykoski M, Giniatullina R, Shakirzyanova A, Bart G, Fayuk D, et al. The role of NMDA and mGluR5 receptors in calcium mobilization and neurotoxicity of homocysteine in trigeminal and cortical neurons and glial cells. J Neurochem. 2014;129(2):264-74.

3. Daggett LP, Sacaan Al, Akong M, Rao SP, Hess SD, Liaw C, et al. Molecular and functional characterization of recombinant human metabotropic glutamate receptor subtype 5. Neuropharmacology. 1995;34(8):871-86.

4. Ohnuma T, Augood SJ, Arai H, McKenna PJ, Emson PC. Expression of the human excitatory amino acid transporter 2 and metabotropic glutamate receptors 3 and 5 in the prefrontal cortex from normal individuals and patients with schizophrenia. Brain Res Mol Brain Res. 1998;56(1-2):207-17.

5. Shigemoto R, Kinoshita A, Wada E, Nomura S, Ohishi H, Takada M, et al. Differential presynaptic localization of metabotropic glutamate receptor subtypes in the rat hippocampus. J Neurosci. 1997;17(19):7503-22.

6. Shigemoto R, Nomura S, Ohishi H, Sugihara H, Nakanishi S, Mizuno N. Immunohistochemical localization of a metabotropic glutamate receptor, mGluR5, in the rat brain. Neurosci Lett. 1993;163(1):53-7.

7. Gereau RW, Conn PJ. Multiple presynaptic metabotropic glutamate receptors modulate excitatory and inhibitory synaptic transmission in hippocampal area CA1. J Neurosci. 1995;15(10):6879-89.

8. Muly EC, Maddox M, Smith Y. Distribution of mGluR1alpha and mGluR5 immunolabeling in primate prefrontal cortex. J Comp Neurol. 2003;467(4):521-35.

9. Renner M, Lacor PN, Velasco PT, Xu J, Contractor A, Klein WL, et al. Deleterious effects of amyloid beta oligomers acting as an extracellular scaffold for mGluR5. Neuron. 2010;66(5):739-54.

10. Um JW, Kaufman AC, Kostylev M, Heiss JK, Stagi M, Takahashi H, et al. Metabotropic glutamate receptor 5 is a coreceptor for Alzheimer abeta oligomer bound to cellular prion protein. Neuron. 2013:79(5):887-902.

11. Haas LT, Salazar SV, Kostylev MA, Um JW, Kaufman AC, Strittmatter SM. Metabotropic glutamate receptor 5 couples cellular prion protein to intracellular signalling in Alzheimer's disease. Brain. 2016;139(Pt 2):526-46.

12. Nygaard $\mathrm{HB}$, van Dyck $\mathrm{CH}$, Strittmatter SM. Fyn kinase inhibition as a novel therapy for Alzheimer's disease. Alzheimers Res Ther. 2014;6(1):8.

13. Kostylev MA, Tuttle MD, Lee S, Klein LE, Takahashi H, Cox TO, et al. Liquid and hydrogel phases of $\operatorname{PrP}(C)$ linked to conformation shifts and triggered by Alzheimer's amyloid-beta oligomers. Mol Cell. 2018;72(3):426-43 e12.

14. Larson M, Sherman MA, Amar F, Nuvolone M, Schneider JA, Bennett DA, et al. The complex PrP(c)-Fyn couples human oligomeric Abeta with pathological tau changes in Alzheimer's disease. J Neurosci. 2012;32(47):16857-71a.

15. Ittner LM, Ke YD, Delerue F, Bi M, Gladbach A, van Eersel J, et al. Dendritic function of tau mediates amyloid-beta toxicity in Alzheimer's disease mouse models. Cell. 2010;142(3):387-97.

16. Haas LT, Salazar SV, Smith LM, Zhao HR, Cox TO, Herber CS, et al. Silent allosteric modulation of mGluR5 maintains glutamate signaling while rescuing Alzheimer's mouse phenotypes. Cell Rep. 2017;20(1):76-88.

17. Fang XT, Eriksson J, Antoni G, Yngve U, Cato L, Lannfelt L, et al. Brain mGluR5 in mice with amyloid beta pathology studied with in vivo [11C]ABP688 PET imaging and ex vivo immunoblotting. Neuropharmacology. 2017:113(Pt A):293-300.

18. Lee M, Lee HJ, Park IS, Park JA, Kwon YJ, Ryu YH, et al. A $\beta$ pathology downregulates brain mGluR5 density in a mouse model of Alzheimer. Neuropharmacology. 2018;133:512-7.

19. Scheff SW, Price DA, Schmitt FA, DeKosky ST, Mufson EJ. Synaptic alterations in CA1 in mild Alzheimer disease and mild cognitive impairment. Neurology. 2007;68(18):1501-8.

20. Scheff SW, Price DA, Schmitt FA, Mufson EJ. Hippocampal synaptic loss in early Alzheimer's disease and mild cognitive impairment. Neurobiol Aging 2006:27(10):1372-84

21. Chen MK, Mecca AP, Naganawa M, Finnema SJ, Toyonaga T, Lin SF, et al. Assessing synaptic density in Alzheimer disease with synaptic vesicle glycoprotein 2A positron emission tomographic imaging. JAMA neurology. 2018:75(10):1215-24

22. Braak H, Alafuzoff I, Arzberger T, Kretzschmar H, Del Tredici K. Staging of Alzheimer disease-associated neurofibrillary pathology using paraffin sections and immunocytochemistry. Acta Neuropathol. 2006;112(4):389-404.

23. Giannakopoulos P, Hof PR, Bouras C. Selective vulnerability of neocortical association areas in Alzheimer's disease. Microsc Res Tech. 1998;43(1):16-23.

24. McKhann GM, Knopman DS, Chertkow H, Hyman BT, Jack CR Jr, Kawas CH, et al. The diagnosis of dementia due to Alzheimer's disease: recommendations from the National Institute on Aging-Alzheimer's Association workgroups on diagnostic guidelines for Alzheimer's disease. Alzheimers Dement. 2011;7(3):263-9.

25. Albert MS, DeKosky ST, Dickson D, Dubois B, Feldman HH, Fox NC, et al. The diagnosis of mild cognitive impairment due to Alzheimer's disease: recommendations from the National Institute on Aging-Alzheimer's Association workgroups on diagnostic guidelines for Alzheimer's disease. Alzheimers Dement. 2011:7(3):270-9.

26. Reiman E, Chen K, Liu X, Bandy D, Yu M, Lee W, et al. Fibrillar amyloid-\{beta\} burden in cognitively normal people at 3 levels of genetic risk for Alzheimer's disease. Proc Natl Acad Sci U S A. 2009;106(16):6820-5. 
27. de Jong HW, van Velden FH, Kloet RW, Buijs FL, Boellaard R, Lammertsma AA. Performance evaluation of the ECAT HRRT: an LSO-LYSO double layer high resolution, high sensitivity scanner. Phys Med Biol. 2007;52(5):1505-26.

28. Carson RE, Barker W, Liow J-S, Adler S, Johnson C. Design of a motioncompensation OSEM list-mode algorithm for resolution-recovery reconstruction of the HRRT. IEEE Nucl Sci Symp Conf Rec. 2003:M16-6.

29. Jin X, Mulnix T, Gallezot JD, Carson RE. Evaluation of motion correction methods in human brain PET imaging--a simulation study based on human motion data. Med Phys. 2013;40(10):102503.

30. Mecca AP, Barcelos NM, Wang S, Bruck A, Nabulsi N, Planeta-Wilson B, et al. Cortical beta-amyloid burden, gray matter, and memory in adults at varying APOE epsilon4 risk for Alzheimer's disease. Neurobiol Aging. 2017;61:207-14.

31. Park E, Sullivan JM, Planeta B, Gallezot JD, Lim K, Lin SF, et al. Test-retest reproducibility of the metabotropic glutamate receptor 5 ligand [(1)(8) F] FPEB with bolus plus constant infusion in humans. Eur J Nucl Med Mol Imaging. 2015;42(10):1530-41.

32. Tzourio-Mazoyer N, Landeau B, Papathanassiou D, Crivello F, Etard O, Delcroix N, et al. Automated anatomical labeling of activations in SPM using a macroscopic anatomical parcellation of the MNI MRI single-subject brain. Neuroimage. 2002;15(1):273-89.

33. Müller-Gartner HW, Links JM, Prince JL, Bryan RN, McVeigh E, Leal JP, et al. Measurement of radiotracer concentration in brain gray matter using positron emission tomography: MRI-based correction for partial volume effects. J Cereb Blood Flow Metab. 1992:12(4):571-83.

34. Innis RB, Cunningham VJ, Delforge J, Fujita M, Gjedde A, Gunn RN, et al. Consensus nomenclature for in vivo imaging of reversibly binding radioligands. J Cereb Blood Flow Metab. 2007;27(9):1533-9.

35. Wu Y, Carson RE. Noise reduction in the simplified reference tissue model for neuroreceptor functional imaging. J Cereb Blood Flow Metab. 2002;22: 1440-52.

36. Carson RE, Channing MA, Blasberg RG, Dunn BB, Cohen RM, Rice KC, et al. Comparison of bolus and infusion methods for receptor quantitation: application to [18F] cyclofoxy and positron emission tomography. J Cereb Blood Flow Metab. 1993;13(1):24-42.

37. Abdallah CG, Hannestad J, Mason GF, Holmes SE, DellaGioia N, Sanacora G, et al. Metabotropic glutamate receptor 5 and glutamate involvement in major depressive disorder: a multimodal imaging study. Biol Psychiatry Cogn Neurosci Neuroimaging. 2017;2(5):449-56.

38. Sullivan JM, Lim K, Labaree D, Lin SF, McCarthy TJ, Seibyl JP, et al. Kinetic analysis of the metabotropic glutamate subtype 5 tracer [(18) F] FPEB in bolus and bolus-plus-constant-infusion studies in humans. J Cereb Blood Flow Metab. 2013;33(4):532-41.

39. Patel S, Hamill TG, Connolly B, Jagoda E, Li W, Gibson RE. Species differences in mGluR5 binding sites in mammalian central nervous system determined using in vitro binding with [18F]F-PEB. Nucl Med Biol. 2007; 34(8):1009-17.

40. Fischl B. FreeSurfer Neuroimage. 2012;62(2):774-81.

41. Buckner RL, Head D, Parker J, Fotenos AF, Marcus D, Morris JC, et al. A unified approach for morphometric and functional data analysis in young, old, and demented adults using automated atlas-based head size normalization: reliability and validation against manual measurement of total intracranial volume. Neuroimage. 2004;23(2):724-38.

42. Oakley H, Cole SL, Logan S, Maus E, Shao P, Craft J, et al. Intraneuronal betaamyloid aggregates, neurodegeneration, and neuron loss in transgenic mice with five familial Alzheimer's disease mutations: potential factors in amyloid plaque formation. J Neurosci. 2006;26(40):10129-40.

43. Müller Herde A, Schibli R, Weber M, Ametamey SM. Metabotropic glutamate receptor subtype 5 is altered in LPS-induced murine neuroinflammation model and in the brains of AD and ALS patients. Eur J Nucl Med Mol Imaging. 2018;46(2):407-420.

44. Um JW, Strittmatter SM. Amyloid-beta induced signaling by cellular prion protein and Fyn kinase in Alzheimer disease. Prion. 2013;7(1):37-41.

\section{Publisher's Note}

Springer Nature remains neutral with regard to jurisdictional claims in published maps and institutional affiliations.

Ready to submit your research? Choose BMC and benefit from:
- fast, convenient online submission
- thorough peer review by experienced researchers in your field
- rapid publication on acceptance
- support for research data, including large and complex data types
- gold Open Access which fosters wider collaboration and increased citations
- maximum visibility for your research: over 100M website views per year
At BMC, research is always in progress.
Learn more biomedcentral.com/submissions

